\title{
Vulvovaginal Candidiasis and its Antifungal Susceptibility Pattern: Single center experience
}

\author{
Rati $\mathbf{R}^{\mathbf{1}}$, Patel $\mathbf{J}^{\mathbf{2}}$, Rishi $\mathbf{S}^{\mathbf{3}}$ \\ ${ }^{1}$ Dr Ruchi Rati, $3^{\text {rd }}$ Year, Post graduate student of Microbiology, ${ }^{2}$ Dr Jaya Patel, $3^{\text {rd }}$ Year, Post graduate student of \\ Obstetric \& Gynecology, ${ }^{3}$ Dr Suman Rishi, Professor, Department of Microbiology. All are affiliated with National \\ Institute of Medical Sciences, Shobhanagar Jaipur, Rajasthan, India.
}

Address for correspondence: Dr Jaya Patel, Email: sunshinejaya@gmail.com

\begin{abstract}
:
Introduction: Candidiasis is the most common vaginal infection affecting about $70 \%$ of women. Our aim was isolation and identification of Candida from high vaginal swabs and in vitro antifungal activity of Fluconazole, Voriconazole, Nystatin, Amphotericin B. Materials and Methods: This study was carried out in NIMS Medical College, Jaipur during June 2013 to May 2014. The study group consisted of 100 women of reproductive age having symptomatic vaginal discharge, vulval purities or lower abdominal pain. High vaginal swabs were collected from each and processed by Gram Staining, culture on Sabroud's dextrose agar \& CHROM agar. Antifungal susceptibility was performed by disc diffusion method as per CLSI guidelines. Results: Vulvovaginal candidiasis accounted for $22 \%$ of cases. Species distribution is as follows: C.albicans 12, C tropicalis 7, C krusei 2, C glabrata 1. Senstivity to Voriconazole was $91.6 \%$ for $C$ albicans, $71.42 \%$ for C.tropicalis, $50 \%$ for C.krusei. Senstivity to Fluconazole was seen in $91.6 \%$ of C.albicans \& $42.85 \%$ of C.tropicalis. C. glabrata was resistant to both Voriconazole \& Fluconazole. Senstivity to Amphotericin B was $75 \%$ for C. albicans, $100 \%$ for C.tropicalis, $100 \%$ for C.krusei \& C. glabrata. Senstivity to Nystatin was $91.6 \%$ for C.albicans \& $100 \%$ for C.tropicalis, C.krusei \& C.glabrata. Conclusions: There is an increase in non-albicans Candida infection and few like C.krusei are intrinsically resistant to azoles. This signifies the need of species identification \& antifungal susceptibility as a routine laboratory procedure in diagnosis of vaginal candidiasis.
\end{abstract}

Key words: Vaginal Candidiasis, Candida, Vulvovaginal candidiasis.

\section{Introduction}

Vulvovaginal candidiasis (VVC) remains one of the most common infections of the female genital tract, which is classified by the world health organization (WHO) as a sexually transmitted disease [1, 2]. Candidiasis is the most common vaginal infection in most countries affecting about $50-72 \%$ of women, 40 $50 \%$ having recurrent episodes[3,4]. The majority of cases of vulvovaginal candidiasis are caused by Candida albicans; however, episodes due to nonalbicans species of Candida appear to be increasing [5,6]. Candida species, mostly C. albicans, can be isolated in the vaginal tracts of 20 to $30 \%$ of healthy asymptomatic non-pregnant women at any single point of time and in up to $70 \%$ if followed longitudinally over a 1 -year period [7]. In about 5 per cent of cases, the Manuscript received: $21^{\text {st }}$ Oct 2014 Reviewed: $6^{\text {th }}$ Nov 2014

Author Corrected: $14^{\text {th }}$ Dec 2014

Accepted for Publication: $28^{\text {th }}$ Dec 2014

International Journal of Medical Research and Review disease has a chronic course, showing frequent and refractory episodes $[5,8]$. Fortunately the infection is rarely life threatening, whereas it is usually associated with such morbidities like discomfort, pain, sexual dysfunctions, vulvar dryness, cracks, itching, burning, soreness and finally health care costs [9-11]. The predisposing factors include: hormonal fluctuations in pregnancy, luteal phase of menstrual cycle, use of oral contraceptives, and hormone replacement therapy among others [12]. Antifungal agents commonly used to treat yeast infections include flucytosine, fluconazole, amphotericin B, voriconazole, clotrimazole, nystatin, capsofungin and ketoconazole. The problem with the use of antifungal agents, apart from safety and cost is the development of drug resistant strains [13]. There is evidence, however of an increased azole resistance among isolates of Candida Species isolated from women with VVC, other Candida are generally more resistant to

Available online at: www.ijmrr.in 72 | P a g e 
azoles than C.albicans [14]. It has been estimated that antifungal therapy was inappropriately prescribed in $54 \%$ of culture negative cases, such unnecessary use of antifungal therapy contributes to the development of antifungal resistance and the emergence of infections associated with other Candida spp. and other opportunistic fungi [15]. Prolonged therapy and increased use of antifungals for recurrent candidiasis are the most common risk factors for azoles resistance among Candida isolates from vulvovaginitis candidiasis patients. Azoles have the advantage of being taken orally, which increase their potency $[9,11,16]$. Most nonalbicans Candida species have higher inhibitory concentrations (MICs) to the azole antifungal agents, and infections they cause are often difficult to treat $[17,18]$. This phenomenon emphasizes the importance of identification and surveillance of the Candida species in the clinical settings. The aim of the study is to find out the prevalence of vulvovaginal candidiasis with special reference to speciation of Candida and susceptibility profile of the Candida species to antifungal agents like amphotericin B, fluconazole, voriconazole \& Nystatin.

\section{Materials and methods}

The study was carried out in the Department of Microbiology, NIMS Medical College and Hospital, Jaipur during the period of 1 year from June 2013 to May 2014. The study group consisted of 100 women of reproductive age group (18-45years), who presented with complaints of symptomatic vaginal discharge, vulval/vaginal pruritis, pain lower abdomen to the department of Obstetrics \& Gynaecology of NIMS. After taking written informed consent, two high vaginal swabs were collected from each of them under all aseptic precautions and immediately sent to the department of Microbiology. Gram staining was performed using one swab while the other swab was used to inoculate Sabourauds Dextrose Agar tubes with Chloramphenicol and CHROM agar plates. These were incubated at $37^{\circ} \mathrm{C}$ for 48 hours. The isolates were identified and speciated using germ tube test and colour of the colonies on CHROM agar plates (HiMedia, India). All the isolates were subjected to antifungal susceptibility testing for amphotericin B, fluconazole, voriconazole, nystatin by disc diffusion method with M44-A Clinical Laboratory Standards(CLSI) guidelines. Disc supplied by Hi-Media, Mumbai were placed on Muller-Hinton agar supplemented with $2 \%$ glucose and $0.5 \mu \mathrm{g} / \mathrm{ml}$ methylene blue. Disk used included Amphotericin B (100 IU), Fluconazole $(25 \mu \mathrm{g})$, Voriconazole $(1 \mu \mathrm{g})$, Nystatin $(50 \mu \mathrm{g})$. After overnight incubation, zone of inhibition were noted. Categorized in susceptible, intermediate and resistance compared with the standard zones interpretive breakpoints published by CLSI M44-A2 [19] Dota KFD et al[20], Rosco Diagnostica[21].

\begin{tabular}{|l|l|l|l|}
\hline Antifungal disc & Susceptible Zone(mm) & $\begin{array}{l}\text { Susceptible dose } \\
\text { dependent Zone(mm) }\end{array}$ & Resistant Zone (mm) \\
\hline Amphotericin b & $>15$ & $10-14$ & $<10$ \\
\hline Fluconazole & $>19$ & $15-18$ & $<15$ \\
\hline Voriconazole & 17 & $16-14$ & $<13$ \\
\hline Nystatin & $>15$ & $10-14$ & $<10$ \\
\hline
\end{tabular}

\section{Results}

During the study period it was found that 22 out of 100 vaginal swabs obtained from women with vulvovaginitis were culture positive for Candida (22\%), while 78 women's vaginal swabs had other causes of vaginitis (Bacterial vaginosis, Trichomoniasis etc). Majority of the women infected belonged to 26-35 years group.

Table 1: Distribution of Candida species isolated from vaginal discharge

\begin{tabular}{|l|l|}
\hline Species identification & Number \\
\hline C.albicans & 12 \\
\hline C.tropicalis & 7 \\
\hline C.krusei & 2 \\
\hline C.glabrata & 1 \\
\hline
\end{tabular}

The predominant species isolated was C.albicans $(\mathrm{n}=12)$. Non-albicans species consisted of C.tropicalis $(\mathrm{n}=7)$, C.krusei $(\mathrm{n}=2)$ and C.glabrata $(\mathrm{n}=1)$. 
Table: 2 Antifungal susceptibility pattern

\begin{tabular}{|l|l|l|l|l|l|l|l|l|l|}
\hline \multirow{2}{*}{$\begin{array}{l}\text { Antifungal } \\
\text { agent }\end{array}$} & \multirow{2}{*}{ No. } & \multicolumn{2}{l|}{ Amphotericin B } & \multicolumn{2}{l|}{ Fluconazole } & \multicolumn{2}{l|}{ Nystatin } & \multicolumn{2}{l|}{ Voriconazole } \\
\cline { 3 - 10 } & & Sensitive & Resistant & Sensitive & Resistant & Sensitive & Resistant & Sensitive & Resistant \\
\hline C.albicans & 12 & 9 & 3 & 11 & 1 & 11 & 1 & 11 & 1 \\
\hline C.tropicalis & 7 & 7 & 0 & 3 & 4 & 7 & 0 & 5 & 2 \\
\hline C.glabrata & 1 & 1 & 0 & 0 & 1 & 1 & 0 & 0 & 1 \\
\hline C.krusei & 2 & 2 & 0 & 0 & 2 & 2 & 0 & 1 & 1 \\
\hline
\end{tabular}

Most of the isolates are sensitive to antifungal like Amphotericin B, Fluconazole, Nystatin \& Variconazole.

Table 3: Predisposing factors for Vaginal Candidiasis

\begin{tabular}{|l|l|l|}
\hline Predisposing Factors & Number Of Patients & Percentage of Isolation \\
\hline Pregnancy & 8 & 37 \\
\hline Oral contraceptives & 6 & 27 \\
\hline Intrauterine devices & 4 & 18 \\
\hline Post antibiotic therapy & 2 & 9 \\
\hline Urinary catheter & 1 & 4.5 \\
\hline Diabetes Mellitus & 1 & 4.5 \\
\hline
\end{tabular}

Pregnancy was the commonest risk factor for VVC 8(37\%) followed by use of oral contraceptive pills 6(27\%). Other risk factors were usage of Intrauterine devices, broad spectrum antibiotics, Diabetes mellitus.[Table 3]

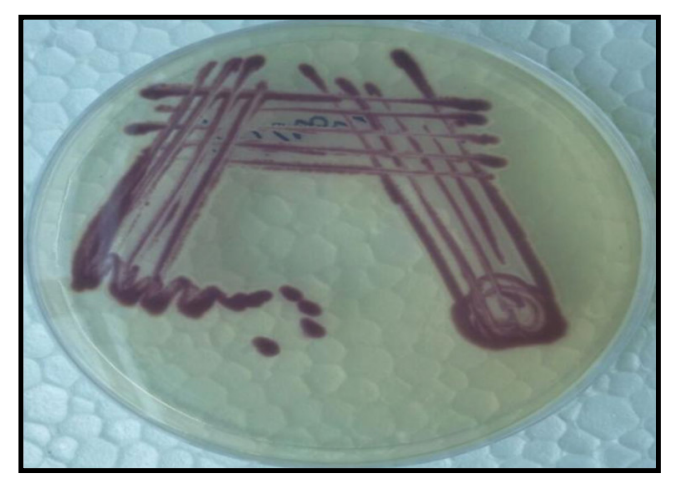

C. Tropicalis on Chrome Agar

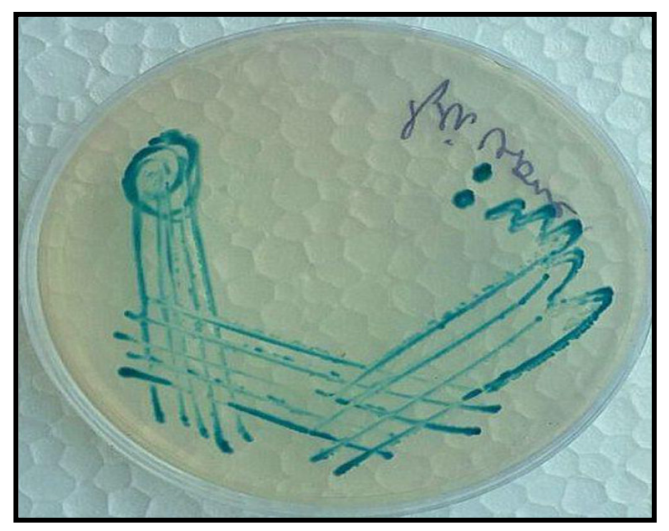

C. Krusei on Chrome Agar

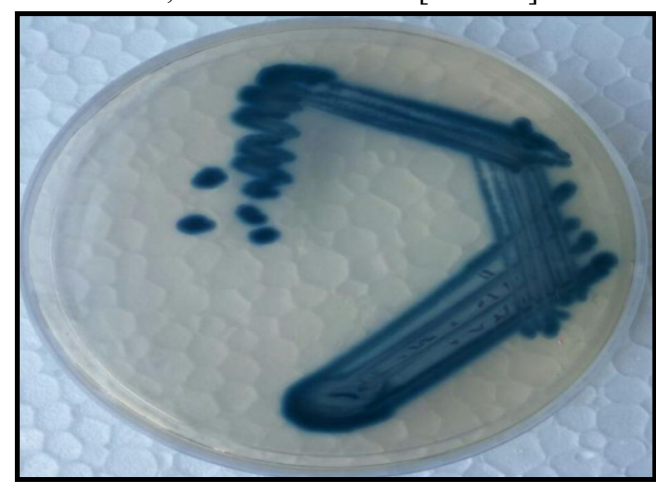

C. Albicans on Chrome Agar

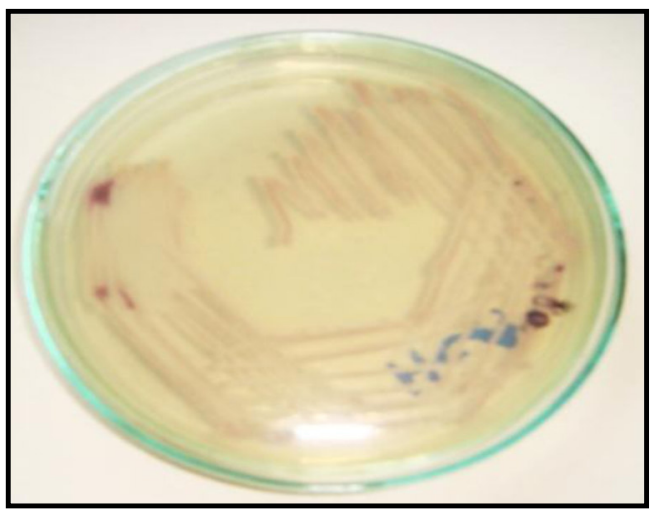

C. Glabrata on Chrome Agar 


\section{Discussion}

Vaginal candidiasis is an extremely common infection. $60-70 \%$ women during their reproductive age have at least one episode of VVC in their lives [22,23]. In our study the highest frequency of vaginal candidiasis was observed in the age group of (26-35) years, followed by age group of (36-45) years. Similar findings were observed by Ako et al [24] who found that vaginal candidiasis occurs most frequently in the age group of 20- 25 years. Sehgal et al also showed the age group 2130 years had the highest incidence of VVC [25]. This shows that the women of childbearing age groups are more vulnerable to vaginal candidiasis. Reason for the high incidence in this age group includes low levels of protective cervical antibodies, increased sexual activity and new influence of reproductive hormones that may lead to increased susceptibility to reproductive tract infections. Our result is in accordance with other studies [26]. In the present study $37 \%$ of the females who presented with the complaint of symptomatic vaginal discharge were pregnant. These are in agreement with studies of Sobel [22], Okungbova et al [27] and Ahmet et al [28]. Use of oral contraceptive pills was found to be associated with $27 \%$ cases of vulvovaginal candidiasis in our study. In this study women of lower socioeconomic strata, poor genital hygiene \& illiteracy showed significantly higher incidence of VVC, use of synthetic clothes could be contributing factor by increasing perineal moisture. Our study is in consistent with work done by Jindal et al [29]. Increased incidence of VVC in the present study was observed with the use of broad spectrum antibiotics. Antibiotic agents increase vaginal yeast colonization and are thought to act by eliminating lactobacilli, thereby facilitating Candida to grow, adhere and germinate. The concept of interaction between lactobacilli and Candida includes competition for nutrients and stearic interference of adherence to vaginal epithelial cells [30,31]. Other important risk factors include Diabetes, use of intrauterine devices and urinary catheters. In this study, culture for Candida species was positive in $22 \%$ of cases. This study is in agreement with the work conducted by Bauters et al [32], who isolated candida species in $20.1 \%$. Mohanty et al.[33], reported $18.5 \%$ prevalence of vulvovaginal candidiasis in a community setting. C.albicans was the most common spp.associated with vulvuvaginitis. This finding is in agreement with other studies who reported that C.albicans is the most predominant species causing vaginal candidiasis.

Table No 4: Candida species isolated in various studies

\begin{tabular}{|l|l|l|l|l|}
\hline Candida species & C. albicans & C. tropicalis & C. krusei & C. glabrata \\
\hline Srujana Mohanty et al, (2003) (\%) & 35.1 & 10.8 & 2.7 & 50.4 \\
\hline Neerja et al, (2005) (\%) & 69.5 & 6.55 & 6.55 & 8.7 \\
\hline Oviasogie et al, (2009) (\%) & 61.5 & 9.4 & - & 25.6 \\
\hline Latha Ragunathan et al, (2010) (\%) & 65 & & & \\
\hline Present study, (2014) (\%) & 54.54 & 31.81 & 9.09 & 4.54 \\
\hline
\end{tabular}

Antifungal susceptibility testing results in our study revealed that none of the non-Candida albicans isolates tested were resistant to AMB and NY. This high AMB and NY susceptibility rate is in agreement with other studies who reported that resistance of Candida species to $\mathrm{AMB}$ and other polyenes appear to be extremely uncommon [33,34,35], partly because of their irreversible fungicidal action once they are bound to the yeast cells [36]. The occurrence of resistance to azole antifungal agents were greater for group of other Candida spp. especially C.glabrata [37,38,34,39]. Many studies emphasized that C.glabrata and C.krusei are intrinsically less sensitive to azoles and some strains of C.tropicalis were resistant to azoles [39], because these organisms are haploid unlike C.albicans which is diploid and drug resistance is more likely to develop during treatment. In the present study $8.4 \%$ C.albicans isolates were resistant to fluconazole, which is in contrast to a study from Brazil involving 56 yeast isolates obtained from women with candidal vaginitis which had no resistant strains to fluconazole [40].

\section{Conclusion}

To conclude, speciation using CHROM agar will help in early speciation and detection of VVC. C. albicans continues to be the major causative agent of vulvovaginal candidiasis. However there is an increase in infections with non-albicans Candida species. The 
emergence of azole resistant $C$. albicans and non albicans species emphasises the need of species identification and antifungal susceptibility as a routine in the diagnosis and management of vaginal candidiasis. The emergence of fluconazole resistance in non albicans Candida may limit its use as a prophylactic agent in hospitals. Early and effective antifungal treatment is the need of the hour for treating the candidial infections. Therefore, routine antifungal susceptibility testing is essential to monitor the emergence of drug resistance. As only a limited number of Candida isolates could be tested in this study, further clinical studies need to be performed involving more number of isolates to confirm the findings.

Funding: Nil

Permission from IRB: Yes

Conflicts of interest: The authors report no conflicts of interest

\section{References}

1.Nyirjesy P, Seeney SM, Grody $\quad$ MH, Jordan CA, Buckley HR. Chronic fungal vaginitis :The value of cultures. Am J Obstet Gynecol. 1995 Sep;173(3 Pt $1): 820-3$.

2. Dota KF, Consolaro ME, Svidzinski TI, Bruschi ML.Antifungal activity of Brazlian propolis microparticales against yeast isolated from vulvovaginal candidiasis . Evid Based Complement Alternat Med. 2011;2011:201953. doi: 10.1093/ecam/neq029. Epub 2011 Mar 9.

3. Esmaeilzadeh S, Omran SM, Rahmani Z. Frequency and etiology of vulvovaginal candidiasis in women referred to a gynecological center in Babol, Iran. Int J Fertil Steril 2009;3:74-7.

4. Nabhan A. Vulvovaginal candidiasis. Ain Shams J Obstet Gynecol 2006;3:73-8.

5. Ferrer J. Vaginal candidosis: epidemiological and etiological factors. Int J Gynaecol Obstet. 2000 Dec;71 Suppl 1:S21-7.

6. Spinillo A, Capuzzo E, Gulminetti R, Marone P, Colonna L, Piazzi G.. Prevalence of and risk factors for fungal vaginitis caused by non-albicans species. Am J Obstet Gynecol. 1997 Jan;176(1 Pt 1):138-41.

7. Simoes JA, Giraldo PC, Faundes A. Prevalence of cervicovaginal infections during gestation and accuracy of clinical diagnosis. Infect Dis Obstet Gynecol 1998;6:129-33.

8. Sobel JD. Candida vulvovaginitis. Sem Dermatol $1996 ; 15: 17-28$.

9. Ehrstrom S, Yu A, Rylander E. Glucose in vaginal secretions before and after oral glucose tolerance testing in women with and without recurrent vulvovaginal candidiasis. Obstet Gynecol. 2006;108 (6):1432-7.

10. Nyirjesy P, Peyton C, Weitz MV, Mathew L, Culhane JF. Causes of chronic vaginitis: analysis of a prospective database of affected women. Obstet Gynecol. 2006;108 (5):1185-91.

11. Paulitsch A, Weger W, Ginter-Hanselmayer G, Marth E, Buzina W. A 5-year (2000-2004) epidemiological survey of Candida and non-Candida yeast species causing vulvovaginal candidiasis in Graz, Austria. Mycoses. 2006;49 (6):471-5.

12. Geiger AM, Foxman B, Gillespie BW. The epidemiology of Vulvovaginal candidiasis among university students. Am. J. Public Health. 1995; 85:1146-8.

13. Pfaller MA, Messer SA, Boyken LB, Rice C, Tendolkar S, Hollis RJ, Doern GV, Diekema DJ. 2005. Global trends in the antifungal susceptibility of Cryptococcus neoformans (1990 to 2004). J. Clin. Microbiol. 43:2163-2167.

14. NormaT G, Arias M L, Moraga M, Baddasarow Y, Jarstrand C.Species distribution and susceptibility to azoles of vaginal yeasts isolated prostitutes. Infec. Dis .Obstet. Gynaecol.2007; 10.1155:1-5.

15. Jackson S T, Mullings AM, Ranford L , and Miller A.The epidemiology of mycotic vulvovaginitis and the use of Antifungal agents in suspected mycotic vulvovaginitis and its implications for clinical practice. West Indian Med.J.2005;54:3:192-95.

16. Aali BS, Tohidi A. Prevalence of Candida vaginitis among symptomatic patients in Kerman. J Qazvin Uni Med Sci. 2000;13:42-8.

17. Richter SS, Galask RP, Messer SA, Hollis RJ, Diekema DJ, Pfaller MA. Antifungal susceptibilities of Candida species causing vulvovaginitis and epidemiology of recurrent cases. J Clin Microbiol. 2005;43 (5):2155-62. 
18. Spinillo A, Capuzzo E, Gulminetti R, Marone P, Colonna L,Piazzi G. Prevalence of and risk factors for fungal vaginitis caused by non-albicans species. Am J Obstet Gynecol 1997;176 : 138-41.

19. Clinical Laboratory Standards Institute(CLSI). Method for antifungal disk diffusion Susceptibility testing of Yeasts; Approved Guideline-second edition. CLSI document M44-A2 (ISBN 1-56238-703-0). Clinical Laboratory Standard Institute, Wayne: Pennsylvania; 2009.

20. Dota KFD, Freitas AR, Consolaro MEL, Svidzinski TIE. A challenge for clinical laboratories: Detection of antifungal resistance in Candida Species causing vulvovaginal candidiasis. Laboratory Medicine 2011;42(2):87-93.

21. Susceptibility testing of yeasts [internet]. 2011 [cited 2011 MAR 16]. Available from : http://rosco.dk/gfx/yeasts.pdf

22. Sobel JD. Vulvovaginal candidosis. Lancet. 2007 Jun 9;369(9577):1961-71.

23. Jacqueline MA, Bettina CF. Candida infections in genitourinary tract. Clin Microbiol Rev. 2010;23(2):253-273.

24. Ako-Nai AK, Kassim OO, Adeniran MO, Taiwo O. A study of urinary tract infections at Ile-Ife, Nigeria. East Afr Med J 1993;70(1):10-14.

25. Sehgal SC, Epidemiology of male urethritis in Nigeria. J Trop Med Hyg. 1990 Apr;93(2):151-2.

26. Sobel JD. Candidal vulvovaginitis. Clin Obstet Gynecol. 1993;36:153-65.

27. Okungbowa FI, ,Isikhuemhen OS, Dede AP, The distribution frequency of Candida species in the genitourinary tract among symptomatic individuals in Nigerian cities. Rev Iberoam Micol. 2003 Jun;20(2):603.

28. Guzel AB, Ilkit M, Burgut R, Ozgunen FT: An evaluation of risk factors in pregnant women with Candida vaginitis and the diagnostic value of simultaneous vaginal and rectal sampling .Mycopathologia. $2011 \mathrm{Jul}$;172(1):25-36. doi: 10.1007/s11046-011-9392-z. Epub 2011 Feb 4.
29. Jindal N, Aggarwal A, Gill P. Significance of Candida culture in women with vulvovaginal symptoms. J Obstet Gynecol India. 2006;56 (2):139-41.

30. Ahmad A, Khan AU. Prevalence of Candida species and potential risk factors for vulvovaginal candidiasis in Aligarh, India. Eur J Obstet Gynecol Reprod Biol. 2009 May;144(1):68-71. doi: 10.1016/j.ejogrb.2008.12.020.

31. Mohanty S, Xess I, Hasan F, Kapil A, Mittal S, Tolosa JE. Prevalence \& susceptibility to fluconazole of Candida species causing vulvovaginitis. Indian J Med Res. 2007;126(3): 216-9.

32. Bauters TG, Dhont MA, Temmerman MI, Nelis HJ. Prevalence of Vulvovaginal Candidiasis and susceptibility to Fluconazole in women. Am J Obstet Gynecol. 2002 Sep;187(3):569-74.

33. Sara A, Laura S,Rossana D, etal . Trends in frequency and in vitro antifungal susceptibility patterns of Candida isolates from women attending the STD out patients clinic of a tertiary care hospital in Northern Italy during the 2002-2007. New Micro. 2009; 32 : 199204.

34. Quindós G, Abarca L, Carrillo-Muñoz AJ, et al. Multicenter survey of in vitro antifungal resistance in yeasts of medical importance isolated from Spanish patients. Rev Iberoam Micol. 1999 Jun;16(2):97-100.

35. Manzano-Gayosso P, Hernández-Hernández F, Méndez-Tovar LJ, González-Monroy J, López-Martínez R. Fungal peritonitis in 15 patients on continuous ambulatory peritoneal dialysis (CAPD). Mycoses. 2003;46(9-10):425-9.

36. Araj GF, Daher NK, Tabbarah LA. Antifungal susceptibility of Candida isolates at the American University of Beirut Medical Center. Int J Antimicrob Agents. 1998 Nov;10(4):291-6.

37. Sobel JD, Zervos M, Reed BD etal. Fluconazole susceptiblity of vaginal isolates obtained from women with complicated Candida vaginitis :Clinical implications. Antimicrob Agents Chemother. 2003 Jan;47(1):34-8.

38. Sandra S R, Rudolph P G, Shawn A M, Richard J H, Daniel J D and Michael A P. Antifungal susceptibility of Candida species causing vulvovaginitis 
and epidemiology of recurrent cases. Amer. Soci. Micro.2005; 43:2155-2162.

39. Akortha E E,Nwaugo V O, Chikwe N O. Antifungal resistance among Candida species from patients with genitourinary tract infection isolated in Benin city, Edo
state,Nigeria. African J.Microl. Research.2009;3:694699.

40. Ribeiro MA, Dietze R, Paula CR, Da-Matta DA, Colombo AL. Susceptibility profile of vaginal yeast isolates from Brazil. Mycopathologia 2000;151:5-10

\section{How to cite this article?}

Rati R, Patel J, Rishi S. Vulvovaginal Candidiasis and its Antifungal Susceptibility Pattern: Single center experience . Int J Med Res Rev 2015;3(1):72-78. doi: 10.17511/ijmrr.2015.i1.12 